\title{
Controle social: entre a contradição e a complementaridade
}

\author{
Social control: the contradiction between and complementarity
}

\author{
Andressa Kolody * \\ Danuta Estrufika Cantoia Luiz **
}

\begin{abstract}
Resumo:
Este artigo pretende refletir sobre as contraditórias relações entre Estado e sociedade civil na sociedade moderna, com enfoque no controle social da segunda sobre o primeiro. Para isso, no decorrer do texto, apresenta-se uma sistematização sobre a categoria controle social, a partir de revisão bibliográfica, e por meio da revisão documental e entrevista analisam-se as concepções e práticas de controle social no contexto do Conselho Municipal dos Direitos da Criança e do Adolescente de Guarapuava. A síntese apresentada se constituiu uma categoria que emerge a partir das falas dos sujeitos participantes no contexto da pesquisa. As reflexões indicam que os diferentes sentidos e conceitos atribuídos ao controle social são produtos das contradições entre capital e trabalho, do contexto histórico, das complexas relações entre Estado e sociedade civil, bem como a concepção e papel atribuídos a essas esferas nos diferentes contextos sociais, econômicos e políticos. Portanto, existe um potencial de controle social nas práticas do Conselho de Direitos analisado, que, no entanto, trata-se de um potencial que não foi desenvolvido, uma vez que o contexto cultural e político de Guarapuava opera para a centralização das decisões e a resistência à partilha de poder no contexto da Política Municipal de Atendimento à Criança e ao Adolescente.
\end{abstract}

Palavras-chave: Controle social. Sociedade civil. Estado. Conselho de direitos.

\begin{abstract}
:
This article aims to reflect on the contradictory relations between state and civil society in modern society, focusing on the social control of the second over the first. For this reason, throughout the text presents a systematic social control over the category, from literature review and through document review and interview analyzes the conceptions and practices of social control in the context of Conselho Municipal dos Direitos da Criança e do Adolescente de Guarapuava. The synthesis presented constituted a category emerging from the speech of the subjects participating in the research context. Reflections indicate that the different meanings and concepts attributed to social control are products of the contradictions between capital and labor, the historical context, the complex relationships between state and civil society, as well as the design and role assigned to these spheres in different social contexts, economic and political, and that therefore there is a potential for social control practices rights Council examined, but it is a potential that has not been developed
\end{abstract}

\footnotetext{
- Professora do departamento de serviço social da Universidade Estadual do Centro Oeste - UNICENTRO. Email: andressakolody@yahoo.com.br.

* Professora Doutora do Programa de Doutorado e Mestrado em Ciências Sociais Aplicadas e Departamento de Serviço Social da Universidade Estadual de Ponta Grossa - UEPG. E-mail: danutaluiz88@gmail.com .
} 
since the cultural and political context of Guarapuava operate for the centralization of decisions and resistance to power sharing in the context of the Municipal Assistance Policy for Children and Adolescents.

Keywords: Social control. Civil society. State. Rights council.

\section{Introdução}

Os temas da participação e do controle social são recorrentes nos estudos sobre políticas sociais. A temática envolve a discussão sobre a própria democracia, e, assim, a relação existente entre Estado e a sociedade civil no mundo moderno. Neste debate, os confrontos de ideias e concepções não são poucos, pelo contrário, refletem as relações de força e interesses tanto no plano teórico como no mais imediatamente político.

O controle social das políticas sociais está previsto na Constituição Federal de 1988, como parte do princípio da participação popular no Estado brasileiro. Assim, os conselhos de políticas públicas e as conferências desenvolvidas por eles são regulamentados como instrumentos privilegiados de controle social sobre as ações estatais. Instituídos nas três esferas de governo, os conselhos possibilitam aos segmentos organizados da sociedade civil a participação na formulação, implementação e avaliação das políticas públicas. É sobre esse legado que se forjam os elementos do controle social democrático.

A partir de então, o controle social expressa um projeto para novas relações entre Estado-sociedade, "[...] onde a esta cabe estabelecer práticas de vigilância e controle sobre aquele" (CARVALHO, 1995, p. 8); constituindo-se "[...] um ciclo decisório que envolve o parâmetro do direito, o planejamento, o papel do gestor, o financiamento, o Ministério Público [entre outras instâncias] [...]" (BEHRING, 2001, p. 6).

O controle social revela-se como complemento indispensável ao controle institucional exercido pelos órgãos fiscalizadores. Trata-se da interferência da sociedade civil na gestão, tanto no que se refere ao planejamento quanto à execução e avaliação dos serviços públicos visando ao interesse público, uma forma específica de participação da sociedade em relação direta com o Estado. Pode-se inferir que as características da participação funcionam como aspecto fundante da categoria controle social, já que o controle social é entendido neste estudo como totalidade concreta, enquanto construção que supera a condição de fiscalização. 
Esse processo pode se realizar em espaços de debate, instâncias formais de participação e/ou por meio de mecanismos que possibilitem a troca de informações e debates mais profundos entre uma pluralidade de atores da sociedade e atores do Estado. Os conselhos gestores e de direitos, a partir de suas práticas, configuram-se um dos espaços onde o controle social é atributo primordial de suas competências.

Tais pressupostos são constitutivos de uma concepção democrática de controle social, ou seja, que permite a sociedade civil controlar as ações do Estado/políticas públicas, por meio de mecanismos legais, previstos nas mais diversas legislações nacionais. Porém, a realidade sociopolítica e estudos científicos nos mostram que não há apenas essa concepção que circula e que está sendo materializada nos diversos espaços de gestão político-social e na vida social como um todo.

Diante dessa questão e com alguns dos pressupostos já enunciados na introdução deste estudo, o presente artigo visa traçar uma discussão apontando os diferentes sentidos e conceitos do controle social, a partir de revisão bibliográfica, com o intuito de entender e propagar esclarecimentos sobre a categoria ainda tão desconhecida no âmbito da prática conselhista e também na prática social da sociedade brasileira, bem como identificar no COMDICA os elementos constitutivos do controle social. Para isso, os conselheiros ${ }^{1}$ responderam questões sobre o diálogo e o acompanhamento entre o segmento que representa; o potencial de influência do segmento nas decisões; a perspectiva de mudança a partir da atuação do conselho, sobre o que entendem por controle social e o exercício do controle social pela sociedade civil.

Este estudo se propõe a refletir sobre as contraditórias relações entre Estado e sociedade civil nas práticas de controle social. As reflexões apresentadas compõem os resultados da dissertação de Mestrado em Ciências Sociais Aplicadas pela Universidade Estadual de Ponta Grossa 2010-2011, intitulada Conselho Municipal dos Direitos da Criança e do Adolescente de Guarapuava/PR: a sociedade civil e o controle social.

\section{Aspectos da trajetória do controle social na sociologia clássica}

\footnotetext{
${ }^{1}$ Conselheiros do segmento não governamental serão reconhecidos pelas siglas: $C$ ng-A; Cng-B; Cng-C; Cng-D; Cng-E; Cng-F; Cng-G; Cng-H, os conselheiros do segmento governamental pelas siglas $\mathrm{Cg}-\mathrm{A}$; $\mathrm{Cg}-\mathrm{B}$; $\mathrm{Cg}-\mathrm{C}$; $\mathrm{Cg}-$ D; Cg-E; Cg-F; Cg-G; Cg-H; Conselheiros da gestão atual serão reconhecidos pelas siglas: $\mathrm{Cng}-1$; $\mathrm{Cng}-4$; $\mathrm{Cg}-1$; Conselheira e ex-conselheiro entrevistado serão reconhecidos pelas siglas Cng-2*; Cng-3*.
} 
Ao problematizar o processo que envolve os conselhos de política e de direitos, importa compreender qual é o conceito de controle social que fundamenta as práticas nesses espaços. "Uma vez que o conceito de controle social está no centro das discussões sobre os conselhos de políticas e de direitos e da participação popular inscrita na Constituição Federal de 1988" (CALVI, 2008, p. 10). Para tanto, no que segue, recupera-se aspectos da trajetória dessa categoria.

Segundo Outhwaite e Bottomore (1996), historicamente o controle social configurou-se uma preocupação categórica da Sociologia, de modo que para Hollingshead apud Lakatos e Marconi (2006, p. 236),

[...] a ideia de controle social aparece em primeiro lugar nas obras de Comte, Curso de filosofia positiva (1830-1842) e Política Positiva (1851-1854), surgindo depois nos escritos de Lester Ward, Sociologia dinâmica (1883). Os primeiros autores que utilizaram a expressão controle social foram Small e Vicent, em seu livro Uma introdução ao estudo da sociedade, publicado em 1894. A primeira obra a tratar especificamente deste assunto apareceu em 1901, escrita por Edward Alsworth Ross: Controle Social.

Ross (apud LAKATOS; MARCONI, 2006, p. 236) enfatiza os meios que a sociedade emprega para obter um comportamento ordenado. Explicam as autoras:

[...] com o enfraquecimento dos instintos sociais do homem, o grupo tem de lançar mão de determinados mecanismos sociais a fim de controlar as relações entre seus membros. Estes mecanismos constituem o controle social, que visa regular o comportamento dos indivíduos e propiciar à sociedade ordem e segurança. Assim, quando as "sociedades artificiais civilizados" se distanciam das "comunidades naturais", os controles instintivos do homem são substituídos pelos recursos artificiais: a lei, a opinião pública, a crença, a religião, a sugestão social (tradição, convenções), a influência de certas personalidades marcantes, a ilusão e a avaliação social (LAKATOS; MARCONI, 2006, p. 237).

Ainda sobre as raízes do conceito de controle social, Calvi (2007, p. 112) assevera que:

[...] alguns autores discutam a noção de controle social a partir de Émile Durkheim $^{2}$ sobre a integração social passando pela criação e utilização do termo

\footnotetext{
${ }^{2}$ A preocupação central de Durkheim está voltada ao conjunto da sociedade, logo o problema básico consiste em estabelecer um grau imperativo de organização e regulação da sociedade de acordo com princípios morais, mas sem o uso demasiado da repressão. Conforme a literatura, Durkheim antecipa as questões que perpassam o controle social, contudo a terminologia só vai ser desenvolvida por sociológicos norteamericanos no século XX. Segundo Carvalho (1995), Ross é indicado como o primeiro a utilizar a expressão, porém ambos dão continuidade à perspectiva durkheimiana: "[...] desejava-se entender muito mais as
} 
na sociologia norte-americana até chegar à contraposição com as reflexões de Michel Foucault acerca do poder e na indicação da situação atual desse debate no interior do pensamento social contemporâneo.

Referenciando Guy Rocher, os autores Lakatos e Marconi (2006, p. 236) afirmam que o controle social diz respeito ao "[...] conjunto das sanções positivas e negativas a que uma sociedade recorre para assegurar a conformidade das condutas aos modelos estabelecidos".

[...] os processos e os meios pelos quais o grupo limita os desvios com relação às normas sociais. Em outras palavras, o sistema de controle social de uma sociedade seria o padrão de pressões que ela exerce para manter a ordem e as normas estabelecidas (LAKATOS; MARCONI, 2006, p. 229).

Logo, “[...] as sanções, positivas ou negativas, possuem dupla função: assegurar a conformidade das condutas, permitindo a coesão e o funcionamento das coletividades e, desencorajar o não-conformismo perante as normas estabelecidas" (LAKATOS; MARCONI, 2006, p. 236).

Seguindo este raciocínio, essa categoria descreve a capacidade da sociedade se autorregular, bem como os meios que ela utiliza para induzir a submissão a seus próprios padrões. Assim, a ordem não é mantida apenas, nem sequer, principalmente, por sistemas jurídicos ou sanções formais, mas é produto de instituições, relações e processos sociais mais amplos.

Fichter (apud LAKATOS; MARCONI, 2006) indica que o controle apresenta três classificações gerais: controle positivo e negativo; ${ }^{3}$ controle formal e informal ${ }^{4}$ e controle

raízes da ordem e da harmonia social do que as condições de transformação e da mudança social" (ALVAREZ, 2004, p. 169).

3 "O controle positivo é empregado para orientar o comportamento do indivíduo, levando-o a proceder de acordo com as normas e valores imperantes na sociedade: a conformidade é induzida através de mecanismos como a instrução, a sugestão, a persuasão, o exemplo, os prêmios e as recompensas; o controle negativo atua de outra maneira, levando os indivíduos a se afastarem de determinadas formas de comportamento consideradas antissociais: baseia-se em mecanismos como a proibição, os tabus, as repreensões e as punições" (LAKATOS; MARCONI, 2006, p. 237).

4 "Os controles formais são assim designados em virtude de serem elaborados com a 'intenção expressa de produzir a conformidade social', sendo obrigatórios a todos os indivíduos que participam do grupo, pequeno ou grande, onde são introduzidos. São formais: as leis, os decretos e atos promulgados pelo Estado; as resoluções e as portarias (ainda no âmbito do poder político); os estatutos e regulamentos de um sindicato, empresa, clube ou universidade; os preceitos da Igreja. Os controles informais são atitudes espontâneas que visam aprovar ou desaprovar determinados comportamentos, conforme sejam ou não compatíveis com as normas e valores da sociedade. São deste tipo a fofoca, o ridículo, o riso, a vaia, o aplauso, o apoio e o sorriso de aprovação" (LAKATOS; MARCONI, 2006, p. 238). 
institucional e grupal. ${ }^{5} \mathrm{E}$, em relação à sua natureza, o controle social pode ser interno e externo. O interno emana da própria personalidade do indivíduo,

[...] através da socialização, ele interioriza as normas e valores de seu grupo e, convencido de sua validade, orienta sua ação de acordo com eles. Assim o controle interno é o autocontrole exercido pela vontade consciente do indivíduo, baseado nos princípios, crenças e ideias dominantes em seu grupo e por ele aceitos. Pode funcionar de maneira positiva através da antecipação feita pelo indivíduo em relação ao prazer e a vantagem advindos da aprovação do grupo; em sentido negativo, por meio da antecipação das sanções punitivas em face do comportamento contrário as normas (LAKATOS; MARCONI, 2006, p. 240).

Já o externo origina-se fora do indivíduo, podendo este ser natural, espontâneo e informal ou artificial, organizado e formal. Já em relação ao tipo específico de controle, podemos ter: o educativo, o intelectual (instrução), o religioso, o jurídico, o ético e o econômico. Considerando a agência que exerce o controle, ele pode ser: doméstico (Família), comunitário (Grupos de amizades, clubes, empresas, vizinhança, entre outros), escolar (Escola), eclesiástico (Igreja), estatal (país, estado, município, departamento, província etc.) ou internacional (Organização dos Estados Americanos; Mercado Comum Europeu; Organização do Tratado do Atlântico Norte; Organização das Nações Unidas etc.).

Em resumo, o controle social na tradição sociológica clássica tem sido usado por diversos autores para designar os mecanismos que estabelecem a ordem social disciplinando a sociedade e submetendo os indivíduos a determinados padrões sociais e princípios morais. Assim sendo, assegura a conformidade de comportamento dos indivíduos a um conjunto de regras e princípios prescritos e sancionados. Sendo historicamente usado em seu sentido coercitivo sobre a população para garantir o controle do Estado ou do empresariado sobre as massas.

\section{Entre a contradição e a complementaridade no debate contemporâneo}

\footnotetext{
5 “Nas diferentes sociedades e na mesma sociedade, em diferentes épocas, ocorre a predominância de uma ou outra instituição, de forma que o controle especifico por elas exercido varia de importância. Os padrões institucionalizados orientam e controlam grupos existentes numa sociedade, sendo que sob este aspecto 'os padrões compartilhados de comportamento e a estreita conformidade às normas' evidenciam-se mais no grupo primário do que no secundário. O controle grupal é exercido pelos diferentes grupos sobre seus componentes, variando o rigor e o grau com que atuam [...]" (LAKATOS; MARCONI, 2006, p. 238).
} 
Na tradição marxista, a compreensão do controle social apoia-se nas reflexões de Mészáros (2002), o que implica uma leitura diferente da esboçada. Segundo Mészáros (2002, p. 991),

[...] a função do controle social foi alienada do corpo social e transferida para o capital, que adquiriu, assim, o poder de aglutinar os indivíduos num padrão hierárquico estrutural e funcional, segundo o critério de maior ou menor participação no controle da produção e da distribuição.

Para Calvi (2007, p. 113), no Brasil e no mundo desenvolveu-se um tipo histórico de controle social típico do sistema capitalista, ou seja:

\begin{abstract}
O controle social do capital sobre a sociedade, que procurou (e ainda procura) assegurar a manutenção ampliada e hegemônica do capital em detrimento da força de trabalho. Neste sentido, o Capital se utiliza hegemonicamente do Estado para controlar as classes subalternas e suas organizações. Numa sociedade capitalista como a nossa, historicamente, o controle social que se apresenta como hegemônico, frente à fraca coexistência de outro tipo de controle social, é o que atua na manutenção e acumulação ampliada do capital pela via dos aparelhos estatais. Este é o controle social do capital. Ele se engendra gerando uma desigual divisão social, subordinando o trabalho às leis do "Sistema do Capital" e devastando as liberdades e as identidades dos sujeitos.
\end{abstract}

Mészáros (2002) explica que o controle social do capital é uma construção que permanece sob a divisão social hierarquizada do trabalho e vem se constituindo como o sistema de controle social dominante. Ou seja, o controle social do capital sobre o trabalho implica a fragilização das conquistas sociais, aumento da concentração de renda, o agravamento da questão social, na desmobilização de organizações, lutas e reivindicações coletivas.

No entanto, o controle social do capital é atravessado pela contradição e enfrenta no cotidiano das relações sociais novas práticas de controle social que passam a coexistir num mesmo período histórico. Mesmo que um se faça hegemônico, o controle social do capital não consegue destruir por completo as lutas por emancipação da sociedade.

Para Calvi (2008), a cena contemporânea expressa a retransferência do poder de controle conferido ao capital ao corpo social como um todo, mesmo que de forma necessariamente irracional, graças à irracionalidade inerente ao próprio capital.

Mészáros (2002) explica que se vive uma crescente polarização inerente à crise estrutural do capitalismo que se iniciou nos anos 1970, bem como um momento em que 
se "[...] multiplicam os riscos do [...] colapso de uma série de válvulas de segurança que cumprem um papel vital na perpetuação da sociedade de mercado" (MÉSZÁROS, 2002, p. 984, grifo do autor). Ou seja, vive-se um contexto de adensamento de problemas em que as contradições intensificam-se. Por isso, Mészáros afirma que não é de se surpreender que tenha ganhado importância significativa a

ideia de controle dos trabalhadores [...] ele acaba transferindo potencialidades de controle para as classes trabalhadoras possibilitando a construção de um tipo de controle distinto do controle social do capital. Assim, apreendemos que o conceito de controle social não é unívoco (CALVI, 2007, p. 114).

Correia (2002) afirma que o controle social é movido pela contradição presente na sociedade civil, ora pendendo para a classe dominante, ora para as classes subalternas, a depender da correlação de forças entre essas, em outros termos, correlação entres os projetos políticos.

[...] enquanto a sociedade civil se constitui em campo de luta de classes na disputa pela imposição de projetos societários diferentes ao conjunto da sociedade, este controle poderá ser maior de uma classe ou de outra em determinados momentos, de acordo com a capacidade destas em formar consensos em torno do seu projeto e torná-lo hegemônico (CORREIA, 2002, p. 165).

No Brasil, historicamente e hegemonicamente, a categoria controle social é entendida como controle do Estado ou do empresariado sobre as massas, o controle social é praticado sempre numa perspectiva coativa sobre a população.

Calvi (2008) entende que este controle social é o típico controle social do sistema capitalista. É o controle social do capital sobre a sociedade, “[...] que procurou (e ainda procura) assegurar a manutenção ampliada do capital em detrimento do trabalho. [...], o capital utiliza-se hegemonicamente do Estado para controlar as classes subalternas e suas organizações" (CALVI, 2008, p. 11).

Continua a autora:

Noutras palavras, o controle social que se apresenta como hegemônico frente à fraca coexistência de outro tipo de controle social, é o que atua na manutenção e acumulação ampliada do capital pela via dos aparelhos estatais. Este é o controle social do capital. Ele se engendra gerando uma desigual divisão social, subordinando o trabalho às leis do "Sistema do Capital" e devastando as liberdades e as identidades dos sujeitos (CALVI, 2008, p. 14). 
Não obstante, o conflito entre o controle social defendido pelos setores conservadores (controle social do Estado sobre a sociedade civil) e o controle social defendido pelos setores progressistas (controle da sociedade civil sobre as ações do Estado no campo das políticas sociais e públicas) resulta na inscrição do controle social democrático na Constituição Federal de 1988, bem como na criação de espaços públicos para a sua realização.

A partir de então, o controle social expressa um projeto para novas relações entre Estado-sociedade, "[...] onde a esta cabe estabelecer práticas de vigilância e controle sobre aquele" (CARVALHO, 1995, p. 8). Esse significado emerge no contexto de luta dos movimentos sociais pela redemocratização da sociedade e do Estado brasileiro a partir da década de 1980 e toma forma e conteúdo no aparato jurídico contemporâneo. Nesses termos, o direito ao exercício de poder por parte dos cidadãos, assegurado pela Constituinte no seu artigo 1 의 $\S 1$, materializa-se nos artigos enunciados no quadro que segue:

Quadro 1 - A legalidade da participação e do controle social

\begin{tabular}{|l|l|}
\hline $\begin{array}{l}\text { Artigo 5o XXXIV e } \\
\text { XXXIII }\end{array}$ & $\begin{array}{l}\text { Peticionar junto aos poderes públicos para a defesa de seus direitos; obter certidões em } \\
\text { repartições públicas e esclarecimento de situações de interesse pessoal, coletivo ou geral. }\end{array}$ \\
\hline Artigo 5o - LXXIII & Promover ações judiciais e representações. \\
\hline Artigo 14 & Soberania Popular via sufrágio universal e pelo voto direto e secreto. \\
\hline Artigo 29 - XII & Cooperar por meio de associações no planejamento municipal. \\
\hline Artigo 31 & Fiscalizar as contas municipais. \\
\hline Artigo 37 & Participação do usuário na administração pública direta ou indireta \\
\hline Artigos 61 e § 2 & Iniciativa das leis complementares e ordinárias. \\
\hline Artigo 74 § 2 & Denunciar irregularidades ou ilegalidades. \\
\hline Artigo 194 e VII & Conjunto integrado de ações (poderes públicos e sociedade). \\
\hline Artigo 198 - III & Participação através dos Conselhos de saúde. \\
\hline Artigo 204- II & Participação na formulação e controle da política (Conselhos de assistência). \\
\hline Artigo 206 - VI & Participação na Gestão de Ensino. Gestão democrática do ensino público. \\
\hline Artigo 225 & Defesa do meio ambiente. \\
\hline Artigo 227 & Criança e adolescente: dever da família, da sociedade e do Estado. \\
\hline
\end{tabular}

Fonte: Kolody (2011).

Posterior à Constituição Federal de 1988, a participação e o controle social também são previstos na Lei Complementar no 101 de 2000 (Lei de Responsabilidade Fiscal, artigo 48 e artigo 49) e nas leis orgânicas (BRASIL, 1988).

A Lei Orgânica da Saúde - LOS, (no 8142/90) - prevê no artigo 1o o Conselho de Saúde e a Conferência de Saúde (BRASIL, 1990). Nesse mesmo artigo, aparecem nas seções $\S 2, \S$ 
4 e $\S 5$ a necessidade de participação popular com paridade com relação aos demais segmentos. Quanto à Lei Orgânica da Assistência Social - LOAS (no 8742/93), o artigo 5o estabelece a participação popular na formulação das políticas e no controle das ações (BRASIL, 1993), legitima no artigo 6 as instâncias deliberativas com composição paritária entre governo e sociedade civil, e mais recentemente por meio da Norma Operacional Básica do Sistema Único da Assistência Social - NOB/SUAS (Conselho Nacional de Assistência Social - CNAS, Resolução n. 27/2005).

A Lei de Diretrizes e Bases da Educação Brasileira - LDB (no 9394/96) prevê a participação e o controle nos artigos 5 § 3, artigo 9o $\S 1$ e artigo 14. Já o ECA (Lei no 8069/1990) estabelece no artigo 88 - II, IV e no artigo 132 (BRASIL, 1996).

Contraditoriamente, registra-se a partir de então um controle social diferente do controle social do capital no cenário brasileiro. "Ele inscreve-se dentro do processo de democratização do Estado, nos quais os conselhos caracterizam-se como um dos espaços de sua realização pela via da participação popular" (CALVI, 2007, p. 115). Assim convive-se com diferentes tipos de controle social.

Os processos desencadeados pelos movimentos sociais nas décadas de 1970 e 1980, contemplados na constituinte de 1988 e nas legislações ordinárias, constituem a abertura de uma nova fase para a sociedade brasileira. É sobre esse legado que se forjam os elementos do controle social democrático:

[...] entendido como a possibilidade da sociedade civil organizada de participar da formulação e fiscalização das políticas sociais, bem como acompanhar e fiscalizar as ações do Estado brasileiro em seus três níveis federados. Da mesma forma, os movimentos sociais foram protagonistas no processo de crítica à democracia representativa liberal e na construção da democracia participativa e deliberativa (CALVI, 2007, p. 288).

Behring (2001, p. 6) é bastante contundente ao inferir que o controle social democrático possui um conceito amplo e constitui-se "[...] um ciclo decisório que envolve o parâmetro do direito, o planejamento, o papel do gestor, o financiamento, o Ministério Público [entre outras instâncias] [...]". Os conselhos possuem uma potencialidade na área das políticas sociais e no controle social "democrático". Ele é um dos elementos constitutivos de uma "esfera pública" ampliada e democrática, ou seja, as novas formas de controle social levam à gestão participativa, por meio de um cidadão ativo, qualificado para 
interferir na gestão, privilegiando aquilo que é público, o bem comum e o interesse de todos. Mas, ao estudá-los ou ocupá-los, é essencial considerar que esse controle social não se limita à instituição legal dos conselhos.

Segundo Nogueira (2004, p. 146), essas novas formas de gestão participativa “[...] promovem um novo vínculo entre representante e representado, tanto no sentido de que alarga e reformula a representação quanto no sentido de que dá novo valor e novo espaço à democracia participativa". Correia (2002) compõe o argumento assinalando que o controle da sociedade sobre as ações do Estado possibilita às classes subalternas ter o domínio sobre as ações em direção ao atendimento de seus interesses.

De igual sorte, os espaços de participação e deliberação no âmbito das políticas sociais, como indicam Nogueira (2004), Dagnino, Olivera e Panfichi (2006), são perpassados pela contraditoriedade dos interesses de classes e seus projetos políticos. O que implica diferentes sentidos do controle social.

Por exemplo, os conselhos e conferências, ao mesmo tempo que carregam o potencial de participação das classes subalternas na gestão das políticas públicas, estão constantemente atravessados por estratégias de consenso e legitimação dos interesses da classe dominantes como elucida Correia (2002, p. 122):

[...] mecanismos de controle do Estado sobre as [...] classes [trabalhadoras e subalternas], à medida que formam consensos em torno das mudanças nas políticas públicas de acordo com as solicitações para expansão do capital, diante do enfrentamento da atual crise, no sentido de realizar cortes nos gastos sociais e privatizar e focalizar as políticas sociais.

Nas palavras de Favreto, ${ }^{6}$ a lei não pode estreitar e nem condicionar os procedimentos de participação, entretanto, além do que está previsto na constituinte e nas legislações ordinárias, há que existir vontade política e capacidade de mobilização.

Os conselhos e as conferências são estruturados a partir do controle social "democrático", o que não significa que outras práticas de controle social não atravessem tais espaços. Importa compreender que os avanços democráticos não caracterizam a supressão do controle social do trabalho discutido por Mészáros, pois a movimentação do social na década de 1980 não logrou outra sociabilidade para além do capital.

\footnotetext{
${ }^{6}$ Palestra proferida no dia 28 de março de 2011, na Universidade de Caxias do Sul, Painel II Eixo Temático Direito e Democracia, sobre o tema $O$ Direito à participação popular na gestão pública.
} 
Para Calvi (2007), o controle social "democrático" tem seus limites nas fronteiras das políticas sociais e públicas. Ou seja, por mais que tenha sido um avanço na sociedade brasileira, o controle social "democrático" limita-se ao âmbito das políticas sociais e públicas. E, mesmo assim, esse controle social encontra inúmeros obstáculos quando objetiva mudanças democráticas na direção de tais políticas. Nesse sentido, a autora argumenta que para pensar os conselhos é essencial apreender que:

[...] no intuito de efetivar um controle social "democrático", eles estão subordinados ao controle social do capital, que usa de todos os artifícios, por meio do Estado, para emperrar os processos decisórios onde as classes subalternas têm voz e voto. Os Conselhos, pautados no controle social "democrático" das políticas sociais, encontram inúmeros obstáculos postos pela lógica do controle social do capital e do Estado para a realização de sua dinâmica e funcionamento. De um lado, os Conselhos deparam-se com os traços conservadores da política nacional como o autoritarismo e o clientelismo. Os poderes executivos nos três níveis federados ainda apresentam forte resistência em dividir espaços nos processos decisórios das políticas sociais com os Conselhos. Assim, lançam inúmeras estratégias contrárias à autonomia dos mesmos. De outro lado, os Conselhos também se deparam com as estratégias de despolitização da sociedade civil e dos espaços públicos lançadas pelo projeto neoliberal (CALVI, 2007, p. 290).

Para a autora em tela, essa possibilidade desenvolve-se na processual politização das relações sociais para o enfrentamento da questão social, mediante a construção de estratégias emancipatórias e de controle social por parte das classes subalternas e da intervenção consciente dessas mesmas classes no movimento histórico. $O$ estabelecimento de um adequado sistema de controle social do trabalho requer o mais ativo envolvimento de toda a comunidade de produtores.

Desta maneira, observa-se que no Brasil, apesar dos avanços constitucionais de 1988, as energias criativas dos diversos grupos sociais continuaram reprimidas e a participação da sociedade civil nos momentos decisórios ficou confinada a "decidir a cor dos postes locais", o calçamento das ruas ou ao remanejamento de metas e recursos de uma política social para outra. Ou seja, o controle social "democrático" limita-se ao campo da elaboração, implementação e fiscalização das ações do Estado no âmbito das políticas sociais e públicas. As lutas das classes subalternas e dos setores progressistas democráticos resultaram apenas na possibilidade da sociedade civil organizada participar da formulação e fiscalização das políticas sociais nos três níveis federados (CALVI, 2007, p. 118).

A partir das considerações da autora, entende-se que nas décadas de 1970 e 1980, processa-se certa agudização das forças políticas que abrem possibilidades e o 
reconhecimento do imperativo de um novo tipo de controle social, contudo continua-se sob a hegemonia e o controle social do capital, pois "[...] o capital é um modo de controle que se sobrepõe tudo o mais". Porém,

[...] reconhecemos e acreditamos no potencial do controle social "democrático" conquistado constitucionalmente, pois ele é fruto de lutas e demandas populares e de pressões da sociedade civil pela redemocratização da nossa sociedade, mostrando que a capacidade de resistência democrática ainda está viva. Porém, é preciso esclarecer que ele se faz subordinado a uma lógica de controle social mais amplo, perverso e poderoso. Ele continua subordinado ao controle social do capital, que usa de todos os artifícios para emperrar os processos decisórios em que a sociedade civil tem voz e voto para decidir, entre eles, os Conselhos (CALVI, 2007, p. 118).

Com a institucionalização, os conselhos portam a legalidade da participação social na perspectiva do controle social "democrático". Todavia, para Duriguetto, ${ }^{7}$ a potencialidade dos conselhos passa pela via do fortalecimento da sociedade, da capacitação e, sobretudo, pela articulação para além do espaço institucionalizado no âmbito dos conselhos, em lutas sociais mais amplas que tenham a perspectiva de classe social com estratégia organizadora dessas.

Logo, o projeto de gestão partilhada sob a potencialidade do controle social do Estado pela sociedade precisa ser enfrentado cotidianamente, reconstruído e desconstruído, sobretudo portado e exercido nos espaços possíveis conquistando espaços contra-hegemônicos.

\section{A concepção e as práticas de controle social no COMDICA em Guarapuava}

Muito embora, historicamente e hegemonicamente, o controle social seja materializado pelo Estado ou empresariado numa perspectiva coercitiva sobre a população, a partir dos processos de redemocratização, o controle social passa a portar um projeto para novas relações entre Estado e sociedade, de modo que ao segundo cabe a responsabilidade de controlar o primeiro. Ao serem questionados, durante a entrevista, sobre o que representa o controle social, ao mesmo tempo que $80 \%$ dos entrevistados

\footnotetext{
7 Palestra proferida no dia 23 de março de 2011, na Universidade Estadual de Ponta Grossa sobre o tema Sociedade Civil e Democracia.
} 
relevam a compreensão sobre essa categoria, apontam o controle social como atribuição do conselho.

Pressupõe-se que a comunicação é dimensão determinante para o exercício do controle social, tanto no que diz respeito à interlocução com a sociedade quanto em sua capacidade de localizar e reunir as informações necessárias, interpretá-las e utilizá-las para produzir argumentações nos processos dialógicos de participação. Sendo estratégia essencial na promoção da democracia participativa, o exercício do diálogo constitui-se também um desafio aos conselheiros como interlocutores das entidades que representam.

Além do respeito à diferença, a efetivação dos conselhos como espaços de representação plural parece estar também relacionada à natureza das relações estabelecidas entre os conselheiros e as entidades/secretarias. Quanto mais forte a relação conselheiro-entidade, maior a possibilidade de que diferentes interesses possam de fato fazer representar (TATAGIBA, 2002).

De uma forma geral, os conselheiros não governamentais têm encontrado pouco respaldo e acompanhamento de suas ações por parte dos representados. Quando se trata do diálogo entre o segmento sociedade civil e do necessário acompanhamento das decisões tomadas junto ao COMDICA, a partir do formulário de dados, registra-se que $37,5 \%$ afirmam que o diálogo é constante, enquanto que $25 \%$ afirmam que isso nunca acontece. Já no que tange ao acompanhamento, 12,5\% diz que o segmento acompanha e $25 \%$ assevera que o acompanhamento nunca acontece.

Pressupondo que os conselhos são, em tese, espaços onde se manifestam os interesses dos diferentes segmentos sociais, possibilitando a negociação de propostas e o direcionamento de recursos para diferentes prioridades, 50\% dos conselheiros afirmam que o segmento influencia no COMDICA, 37,5\% dizem ser fundamental e 12,5\% não responderam. A contradição maior está na inexistência de relações dialógicas entre o representante e o segmento, quando legalmente essas deveriam ser complementares.

Mediante as entrevistas, é possível identificar uma confluência entre entidade e segmento. Parece correto afirmar que ao serem questionados sobre o diálogo e o acompanhamento entre o segmento, as respostas dizem respeito ao diálogo e acompanhamento da entidade a qual o conselheiro está vinculado. Considera-se que 
compreender essa confluência demanda pensar na frágil relação entre representante e representado, desvelada pelos depoimentos a seguir.

Segundo os conselheiros não governamentais, "[...] com o segmento ainda não acontece uma divulgação, um diálogo" (Cng-1). Acaba que "[...] as discussões ficam somente de conhecimento do conselheiro participante" (Cng-2*).

"Está muito centralizado na pessoa do conselheiro. Eu represento um segmento que está praticamente desarticulado, muitos não sabem nem que são representados no conselho da criança" (Cng-3*). Sobre a "[...] devolutiva para o segmento, eu nunca ouvi falar da existência dessa prática, não tenho conhecimento de como fazem o repasse dessas informações do que acontece, não sei se chega e como chega" (Cng-4).

A política brasileira, nos termos da democracia representativa também tem vivenciado impasses semelhantes, uma vez que tem se tornado prática comum eleger os representantes, mas não acompanhá-los em seus mandados. Portanto, se não houver exercícios anteriores, concretos, por meio dos quais se aprenda e se conquiste acesso aos níveis decisórios de intervenção, como esperar que os conselheiros atuem democraticamente se a democracia é uma prática estranha no cotidiano; sequer internamente as entidades contam com estruturas participativas e as comunidades não dispõem de espaços significativos de intervenção nas políticas sociais. Ou seja, a relação entre democracia representativa e participativa, que deveria ser complementar (segundo os preceitos legais), é contraditória. A contradição reside na prevalência de dois predicados (papel de direito e papel de fato) no mesmo sujeito (COMDICA).

No que tange à representatividade dos conselheiros governamentais, também se visualiza uma relação frágil entre representantes e órgãos de origem. Essa política de esvaziamento tem se refletido no alto índice de ausência dos conselheiros governamentais nas reuniões do COMDICA, bem como a sua rotatividade, o que enfraquece os conselhos que, “[...] apesar de suas prerrogativas legais, não conseguem impedir que muitas questões importantes sejam decididas nos gabinetes dos altos escalões do governo, sob a influência dos interlocutores tradicionais" (TATAGIBA, 2002, p. 63).

As falas dos sujeitos recuperam a ausência de uma via de mão dupla entre conselhos, secretarias, segmentos e/ou entidades, onde as pautas do conselho nem sempre são 
discutidas, e a posição dos representados nem sempre chega ao conhecimento do conselho, de forma a interfeir na deliberação.

Com isso, os conselheiros acabam emitindo sua própria opinião sobre determinado tema, resultado do seu acúmulo pessoal ou da sua adesão às propostas defendidas no calor do debate. Essa falta de um debate prévio com as entidades e movimentos de origem tem se mostrado muito problemática [...] esse distanciamento dos conselhos em relação às entidades sociais e aos órgãos da administração pública responsáveis pela execução das políticas, para além dos efeitos negativos relatados, traz ainda como consequência perversa a baixa visibilidade social dos conselhos. Ou seja, se por um lado, as deficências na comunicação dos conselheiros com suas bases se traduzem na conformação de públicos fracos no processo deliberativo no interior dos conselhos, por outro lado, as fissuras na comunicação diminuem a força dos conselhso enquanto públicos que disputam numa esfera pública mais ampla. Sem capilaridade social, os conselhos são levados ao isolamente e à debilidade. Essa é a condição atual de muitos conselhos [...] (TATAGIBA, 2002, p. 66).

É preciso ampliar cada vez mais o grau de publicidade dos espaços de negociação e construir espaços públicos nos quais um número cada vez maior de interesses faça-se representar. É nesses espaços ampliados que tendências ao corporativismo podem ser confrontadas e o aprendizado da difícil construção do interesse público pode avançar.

Assim, os sujeitos foram indagados sobre a publicização e socialização das decisões do COMDICA para a comunidade e para o segmento ou secretaria que representam. $E$, segundo os entrevistados, "Não acontece, há uma divulgação mais ampla no que se referem algumas questões, a exemplo do FIA. [...] o conselho não realiza uma devolutiva para a comunidade sobre seu papel, deliberações. [...] e com o segmento ainda não acontece uma divulgação, um diálogo" (Cng-1).

Como demonstram os registros, as respostas perpassam um eixo comum: a precária publicização: "Infelizmente não há divulgação para comunidade e também nem aos outros membros da entidade. As discussões ficam somente de conhecimento do conselheiro participante" (Cng-2*).

Os meios de comunicação do conselho hoje são os oficiais, os boletins informativos. Não existe um veículo de comunicação, a não ser o interno. Se você perguntar na comunidade em geral você vai ver que ninguém sabe direito o que é o conselho, o que ele faz, nem sabem que ele existe [...](Cng-4).

Atualmente nem o conselho discute o que lhe compete e nem o retorno acontece. Então, qual é a resposta que eu dou para o meu segmento? Praticamente 
nenhuma, a não ser quando se trata do FIA ${ }^{8}$. O retorno tem ocorrido somente em casos particulares. A pauta do conselho hoje é uma pauta muito específica, coisas pequenas e a discussão sobre a política e o retorno para as entidades não está acontecendo. Não há uma cobrança pelo segmento, até por que o conselho precisa discutir a composição [...] (Cng-3*).

Por se tratar de um ciclo decisório que envolve o parâmetro do direito, o planejamento, o papel do gestor, o financiamento, bem como outras instâncias, procurase analisar as práticas de controle social que os sujeitos entrevistados portam em contraposição às concepções que defendem. A este respeito, Cg-1 avalia que "[...] 0 controle social está ao contrário: primeiro, nós estamos vendo o problema para então resolver". Dessa forma, "[...] o COMDICA faz controle social só que ele faz quando o problema já se instalou".

A afirmação que o COMDICA faz sobre controle social contrapõe-se à própria concepção dos entrevistados sobre essa categoria, pois se trata de interferências no desenho, monitoramento e fiscalização da política em questão. Qual é então o potencial de controle que possui um órgão que age de forma imediatista e pontual?

O controle social é produto das contraditórias e complementares relações entre Estado e sociedade civil, no entanto, defende-se nesse estudo que as classes subalternas têm que se fazer presente, serem representadas e ocupar de forma ética e política os espaços possíveis, apropriar-se e materializar a democracia participativa.

A respeito do exercício do controle social pela sociedade civil, um dos sujeitos participantes afirma que "[...] o segmento sociedade civil faz controle social, uma vez que esta lá [...]" (Cng-3*), contudo a existência meramente legal do espaço não é sinônimo de controle social. Tanto o COMDICA quanto os demais espaços de participação política, segundo as literaturas na área, carecem de uma ocupação hegemônica e política, de modo a inscrever de fato as demandas dos representados no âmbito do Estado.

Tanto a elaboração e promulgação da legislação instituidora dos conselhos específicos quanto a sua materialidade envolvem claramente um processo de luta que explicita a diversidade de projetos políticos e interesses em jogo, bem como o apreço desigual que cada um desses grupos tem com a proposta de controle social por meio dos conselhos (CARVALHO, 1995).

\footnotetext{
${ }^{8}$ Fundo para a Infância e Adolescência
} 
Em relação às práticas de controle social, um dos entrevistados defende que "[...] cada um faz controle social de sua forma, nem todos compreendem o que é e as implicações que advém dessa atribuição do conselho" (Cng-1). Tal declaração opõe-se ao próprio significado social e legal que portam os conselhos, pois se trata de um sujeito coletivo e a ele compete o controle social. Muito embora as práticas de todos os conselheiros personifiquem e materializem esse atributo, é importante e necessário compreender que não se trata de um projeto individual. Pelo contrário, o potencial reside justamente na possibilidade de relação, entre os segmentos e entre Estado e sociedade civil, em um movimento contínuo entre representante e representado, o qual deve ser eminentemente coletivo.

A ausência de compreensão acerca do atributo controle social é algo possível de desenvolver e se apropriar, afinal participar é um processo pedagógico, em que a participação política constrói-se e se qualifica. Mas chamam atenção as afirmações de dois entrevistados: "O segmento procura fazer controle social, [...]. Nesse meio tem as competências, as obrigações e as parcerias, isso acaba interferindo. Às vezes tem coisas que eu não quero controlar muito, não me interessa. Amortece a função do conselheiro, acaba fazendo de conta" (Cng-4).

Se as competências e atribuições do COMDICA são relegadas às relações de poder que se estabelecem nas relações entre Estado e sociedade, "O segmento sociedade civil não faz controle social, na verdade ele nem sabe o que é controle social. Na atualidade, o segmento da sociedade civil tem somente uma preocupação que se chama dinheiro" (Cng$\left.2^{*}\right)$.

Parece correto afirmar que o controle social oculta uma estratégia de legitimação da ordem existente e não sua função de participação e resistência, o que pode colocar em risco qualquer tentativa de democratização na área da criança e do adolescente.

Considerando o depoimento, as práticas conselhistas do segmento sociedade civil parece se vincular à subordinação política em detrimento das tendências contrahegemônicas no atendimento das demandas infanto-juvenis. Dessa forma,

[...] Quando se fala em cifras, os segmentos da sociedade civil buscam, cada um, o que é de seu interesse. O controle social, não fica somente em segundo plano, mas em último... Entendo que estamos vivendo um momento em que o que dita as "regras" é o recurso que a instituição vai receber, e se para isso for necessário 
fechar "acordos obscuros", eles serão fechados. Então, por que falar em controle social? (Cng-2*).

As análises demonstram que contraditoriamente, ao mesmo tempo que parece se legitimar um Estado apartado da sociedade civil, o segmento sociedade civil protagoniza a ocupação do espaço de participação política (COMDICA). Delimitando que tem uma "função estatal", a qual objetiva a tendência de transformação da realidade no tocante a essa população. Verifica-se certo enfrentamento para ver inscrita a participação na gestão da política pública. Contudo, expressam por meio de suas práticas os interesses divergentes entre o próprio segmento e a carência por ações políticas deliberadas e projetos coletivos, pactuados e consensuados enquanto categoria coletiva.

A sociedade civil no COMDICA apresenta menor desenvoltura frente ao processo democrático político. Luiz (2005) defende a partir da filosofia política de Gramsci, a importância da elevação ética e política dos segmentos da sociedade civil à estruturação da sociedade política, num plano em que há táticas e estratégias, denominadas guerra de posição. ${ }^{9}$ Trata-se de um processo que demanda resistência, articulação para se fortalecer enquanto segmento e inserção crítica de sujeitos concretos na vida social, elementos estes que podem compor uma contra-hegemonia.

A sociedade civil não é a extensão da vida democrática, é lugar de interesses conflitantes e possíveis de compor um projeto coletivo mediante consenso. Nesse aspecto, o depoimento do conselheiro, que segue, avalia e indica como avançar nessa trajetória:

[...] eu acho que a gente tem muito o que caminhar, estamos muito segmentados [...]. Eu acho que falta esse construir junto, somar, para que realmente a sociedade perceba que está sendo feito algo por ela e com ela. É muito fácil de a gente pensar as coisas e trazer pronto, sem considerar as realidades, necessidades e mesmo a opinião da comunidade a respeito. Envolvimento de toda sociedade, do poder público, da sociedade civil organizada, da sociedade civil desorganizada, do público em geral, isso é muito desafiante, e eu não sei se um dia a gente vai conseguir fazer isso ser algo que realmente caminhe junto, que trabalhe e que faça as coisas acontecerem. O que eu percebo é que ele está cada um fazendo, dizendo que está fazendo sua parte bem feita, de repente que é o mais interessado, está ilhado. A sociedade civil organizada diz que está organizada e está fazendo, o poder público diz que está organizado e está fazendo e o público que tem que ser atendido diz que ninguém está fazendo nada por eles (Cng-4).

\footnotetext{
${ }^{9}$ Para saber mais sobre guerra de posição consultar Gramsci (1989 apud LUIZ, 2005).
} 
Há que se considerar ainda que, para que a construção do interesse coletivo avance, além do espaço de participação, é eminente o engajamento político dos atores sociais, "sair de si e pensar no outro" (NOGUEIRA, 2004, p. 63). O engajamento enseja compromisso e a crença no potencial de mudança a partir das relações entre Estado e sociedade civil.

O depoimento acima expõe que em Guarapuava inexiste uma relação articulada, o que reafirma a contradição entre as concepções e práticas de controle democrático, já que no plano da retórica, segundo Cng-4, os envolvidos se definem dizendo que "estão fazendo a sua parte", mas não há preocupação de articular os fragmentos Estado e sociedade.

A respeito do potencial do COMDICA na alteração da situação infanto-juvenil, o segmento governamental tem uma maior compreensão da potencialidade do COMDICA perante o controle social da política, mas centraliza as decisões, enquanto o segmento não governamental convive com as relações que perpassam a partilha de poder com vistas ao controle da política e afirmam um menor potencial de influência.

O segmento sociedade civil, por vivenciar os limites da ocupação do COMDICA, do processo decisório e do acesso às informações do orçamento e da política, desvela a contradição entre a compreensão do papel de direito e a tendência de materialização do papel de fato. Isso parece indicar que nessa correlação de forças entre projetos vige o controle social tradicional e não o controle democrático, ou seja, o Estado ainda controla a sociedade no que concerne a gestão da política da criança e do adolescente. Razão pela qual o segmento sociedade civil tem uma crença menor no potencial de mudança a partir da atuação do conselho.

Siqueira (2006) e Nogueira (2004) lembram que quando a sociedade não se reconhece nas tomadas de decisão do Estado - já que essas, por vezes, respondem aos interesses particulares de alguns segmentos específicos da sociedade, os canais de mediação do processo de construção do interesse coletivo - perdem legitimidade e visibilidade pública. O que implica uma confusão entre os interesses privados e os interesses públicos, logo a sociedade civil não reconhece como legítimas as ações estatais.

O debate político dentro do Estado, e ainda a construção de práticas de controle social que interfiram de fato no planejamento, execução e fiscalização de políticas públicas, é muito mais complexo do que o reconhecimento legal desses espaços e da abertura para 
a participação, pois o processo de interiorização e exteriorização de uma nova cultura leva muito mais tempo que o movimento legal que envolve tal temática.

\section{Considerações finais}

A breve exposição sobre o controle social adverte que os diferentes sentidos e conceitos atribuídos ao controle social são produtos das contradições entre capital e trabalho, do contexto histórico, das complexas relações entre Estado e sociedade civil, bem como a concepção e papel atribuídos a essas esferas nos diferentes contextos sociais, econômicos e políticos.

Na medida em que a concepção de Estado é restrita e funcional aos interesses da classe dominantes, o controle social que detém a hegemonia é o controle social do capital. Aqui, o Estado é "[...] um órgão de dominação de classe por excelência, com vistas à promoção de um controle social que garanta o consenso social para a aceitação da ordem do capital [...]". Essa concepção compreende um “[...] Estado que controla a sociedade em favor dos interesses da classe dominante por meio da implementação de políticas sociais para amenizar os conflitos de classes [...]" (CORREIA, 2002, p. 120).

Por exemplo, no contexto do Estado Liberal, o papel do Estado volta-se exclusivamente aos interesses particulares da classe dominantes, imediatamente a via de controle assenta-se sobre a coerção, negando qualquer possibilidade de formulação das políticas sociais.

Nas contraditórias relações entre Estado e sociedade civil, verifica-se uma gradativa socialização do Estado, "[...] o que mostra que é possível mesmo sob a dominação burguesa e de um Estado capitalista, ter espaço para representação de interesses de outras classes" (CALVI, 2007, p. 120).

Com a demarcação de novas tendências, voltadas à possível ampliação do Estado, este passa a ser "[...] um espaço contraditório, que apesar de representar hegemonicamente os interesses da classe dominante, incorpora demandas das classes subalternas" (CORREIA, 2002, p. 121). No entanto, mesmo com essa nova configuração do Estado, não há o predomínio dos interesses coletivos e do controle social do trabalho; “[...] existe a possibilidade da coexistência de diferentes projetos políticos cada qual com um 
conceito de controle social, graças à agudização dos antagonismos de classes e da contradição capital X trabalho" (CALVI, 2007, p. 119).

Por mais que os fatos indiquem a abertura de flancos, outras tendências e possibilidades, o Estado permanece capitalista. Nesse contexto, “[...] o que define o atendimento dos direitos sociais, dos interesses plurais, a ampliação das políticas sociais é a correlação de forças entre o trabalho e o capital" (CALVI, 2007, p. 120).

O que possibilita a hegemonia de um ou de outro controle social "[...] é a existência de um grupo social que na adoção de uma das perspectivas se constitui como dirigente e/ou dominante, isto é, possui a hegemonia e/ou a dominação na sociedade" (CALVI, 2007, p. 122).

Apreende-se que esse processo não é fácil, pois tanto os conselhos quanto as conferências estão constantemente tensionados pela hegemonia do capital, pelos interesses particularistas, por formas de participações distintas (corporativa, assistencialista, eleitoral e política) e, sobretudo, atravessadas pelo construto neoliberal.

Tensões entre as noções de controle social "democrático", participação, descentralização, publicização e democracia participativa e deliberativa e as noções de controle social do capital e seu comando político, de descentralização, publicização e participação gerencial do projeto neoliberal (CALVI, 2007, p. 288).

Essa é a razão pela qual intitulamos este artigo que aborda diferentes sentidos e conceitos de controle social, como "entre a contradição e a complementaridade", pois estes convivem num mesmo cenário político; porém, mostram-se complementares em determinadas situações e da mesma forma se mostram contraditórios. Tal situação não poderia se mostrar diferente considerando as distintas formas de materialização do controle social num contexto hegemonicamente demarcado pelas contradições do capitalismo, que por si só já expressa várias estratégias de controle social para manter e multiplicar seus preceitos em várias dimensões da vida social.

Mas esse mesmo capitalismo se mostra "democrático" e abre flancos no seu interior, os quais permitem ganhos e conquista de espaços para outras perspectivas de controle social, pela socialização da política e pela força de segmentos que procuram empreender esforços no sentido de materializar elementos contrários ao seu sentido hegemônico. 
Razão pela qual há que se investir na propagação e socialização de tal tendência contemporânea para contribuir no avanço de processos democráticos no Brasil.

Essas contradições se fazem presente no contexto das relações entre Estado e Sociedade no COMDICA em Guarapuava, de modo que o segmento sociedade civil, na relação com o segmento governamental, tem potencial de controle social, mas se trata de um potencial que não foi desenvolvido. Muito embora o controle social democrático esteja legalmente instituído, o contexto cultural e político de Guarapuava bloqueiam para que esse potencial não ganhe força, haja vista a centralização das decisões e a resistência à partilha de poder, para a efetivação do controle democrático da política de atendimento à criança e ao adolescente.

\section{Referências}

ALVAREZ, M. C. Controle social: notas em torno de uma noção polêmica. São Paulo em Perspectiva, São Paulo, v. 18, n. 1, p. 168-176, 2004. Disponível em:

<http://www.scielo.br>. Acesso em: 22 nov. 2010.

BRASIL. Constituição (1988). Constituição da República Federativa do Brasil. Senado Federal: Centro Gráfico, Brasília, 1988.

Lei $n$ o 8.142, de 28 de dezembro de 1990. Dispõe sobre a participação da comunidade na gestão do Sistema Único de Saúde (SUS) e sobre as transferências intergovernamentais de recursos financeiros na área da saúde e dá outras providências. Disponível em: <http://www.planalto.gov.br/ccivil_03/leis//8142.htm>. Acesso em 30 ago. 2014.

Lei no 8.742, de 7 de dezembro de 1993. 1993. Dispõe sobre a organização da Assistência Social e dá outras providências. Disponível em: <http://www.planalto.gov.br/ccivil_03/leis//8742.htm>. Acesso em: 30 ago. 2014.

. Lei no 9.394, de 20 de dezembro de 1996. 1996. Estabelece as diretrizes e bases da educação nacional. Disponível em:

<http://www.planalto.gov.br/ccivil_03/leis/19394.htm>. Acesso em: 30 ago. 2014.

BEHRING, E. R. Controle social: histórico e estratégias de aprimoramento. 2001. Disponível em: <www.cfess.org.br>. Acesso em: 20 maio 2008.

CALVI, K. U. O controle social nos conselhos de políticas e de direitos. Emancipação, Ponta Grossa, v. 8, n. 1, p. 9-20, jan./jun. 2008. 
. Serviço social e conselhos de políticas e de direitos: contradição entre o projeto ético-político e a condição de assalariamento. 2007. 330 p. Dissertação (Mestrado em política social) - Universidade Federal do Espírito Santo, Espírito Santo, 2007.

CARVALHO, A. I. Conselhos de saúde no Brasil: participação cidadã e controle social. Rio de Janeiro: Fase, 1995.

CORREIA, M. V. C. Que controle social na política de assistência social. Revista Serviço Social e Sociedade, São Paulo, v. 1, n. 72, p. 119-144, 2002.

DAGNINO, E.; OLIVERA, A. J.; PANFICHI, A. (Org.). A disputa pela construção democrática na América Latina. São Paulo: Paz e terra, 2006.

KOLODY, A. Conselho Municipal dos Direitos da Criança e do Adolescente de Guarapuava/PR: a sociedade civil e o controle social. 2011. 221p. Dissertação (Mestrado em ciências sociais aplicadas) - Universidade Estadual de Ponta Grossa, Ponta Grossa, 2011.

LAKATOS, E. M; MARCONI, M. A. Sociologia geral. São Paulo: Atlas, 2006.

LUIZ, D. E. C. Rupturas moleculares emancipatórias: a potencialidade da prática do serviço social. 2005. 283p. Tese (Doutorado em serviço social) - Pontifícia Universidade Católica, São Paulo, 2005.

MÉSZÁROS, I. Para além do capital: rumo a uma teoria da transição. São Paulo: Unicamp, 2002.

NOGUEIRA, M. A. Um estado para a sociedade civil: temas éticos e políticos da gestão democrática. São Paulo: Cortez, 2004.

OUTHWAITE, W.; BOTTOMORE, T. Dicionário do pensamento social do século XX. Rio de Janeiro: Jorge Zahar, 1996.

SIQUEIRA, R. B. Conselhos de Política e Participação Democrática: Análise dos Setores Saúde e Assistência Social em PG. Ponta Grossa, 2006. 134p. Dissertação (Mestrado) em Ciências Sociais Aplicadas. Universidade Estadual de Ponta Grossa, 2006.

TATAGIBA, L. Os conselhos gestores e a democratização das políticas públicas no Brasil. In: DAGNINO, E. (Org.). Sociedade civil e espaços públicos no Brasil. São Paulo: Paz e terra, 2002, p. 47-103. 